RESEARCh NOTE

\title{
Calodium hepaticum (Nematoda: Capillaridae) in a red fox (Vulpes vulpes) in Italy with scanning electron microscopy of the eggs
}

\author{
Fabio Macchioni ${ }^{1}$, Luca Chelucci ${ }^{1}$, Lisa Guardone ${ }^{1}$, Walter Mignone ${ }^{2}$, Maria Cristina Prati ${ }^{3}$ and Marta Magi $^{1}$
}

\author{
${ }^{1}$ Department of Veterinary Science, University of Pisa, Pisa, Italy; \\ ${ }^{2}$ Istituto Zooprofilattico Sperimentale of Piedmont, Liguria and Aosta Valley, Imperia, Italy; \\ ${ }^{3}$ Scuola Normale Superiore, Pisa, Italy
}

\begin{abstract}
Calodium hepaticum (Bancroft, 1893) Moravec, 1982 (syn. Capillaria hepatica) is a cosmopolitan capillariid nematode, infecting mainly rodents and occasionally other mammals, including humans. Reports of $C$. hepaticum in canids are rare and the present one is, to the best of our knowledge, the first reported case in a red fox (Vulpes vulpes Linnaeus) in Italy. Scanning electron microscopy (SEM) examination of the eggs of $C$. hepaticum allowed a precise description of the egg morphology, which is one of the most relevant specific characteristics of capillariid nematodes. The egg shell showed a fibrous beam-like network which differs from that of the eggs of closely related trichinelloid species. This characteristic can be useful especially in case of spurious infection, when misdiagnosis among different trichinelloids species can occur.
\end{abstract}

Keywords: Capillaridae, Calodium hepaticum, egg shell, morphology, ultrastructure

Calodium hepaticum (Bancroft, 1893) Moravec, 1982 (syn. Capillaria hepatica) is a zoonotic cosmopolite capillariid nematode, which develops in many species of rodents, such as Apodemus Kaup, Arvicola Lacépède, Clethrionomys Tilesius, Ondatra Link, Rattus Fischer de Waldheim, and occasionally in a very broad range of other mammals (Moravec 2000, Fuehrer et al. 2011). Adult worms live in the liver parenchyma, where they can cause hepatitis, liver fibrosis and eventually death.

The life cycle is direct and unusual (Moravec 2001). Females lay eggs in the liver, where they remain immature for the entire life of the host (Farhang-Azad 1977). Eggs reach the external environment either through decay of the host's carcass or through the shedding of eggs in the faeces of a predator which ingested an infected rodent (spurious infection). In the external environment eggs embryonate in 5-8 weeks and become infective for a new host. Humans can get infected through accidental ingestion of infective eggs with contaminated food or water or in case of "pica" (the habit of eating non-food substances, mainly associated with early childhood or sometimes with psychiatric diseases). For this reason, most human cases occur in children and especially in the case of poor hygienic conditions (Fuehrer et al. 2011).

Reports of C. hepaticum in canids are sporadic and this capillariid species has been found in wild canids in Brazil (Ruas et al. 2003), in a coyote in Canada (Wobeser and Rock 1973), in dogs in Great Britain (Lloyd et al. 2002), Switzerland (Brander et al. 1990) and in the USA (Stokes 1973). Furthermore, it was previously reported in domestic dog by López-Neyra (1947) and Skryabin et al. (1957). As far as we know, the only reported cases of liver infection of the red fox, Vulpes vulpes (Linnaeus), have been described in Slovakia in the 1960s (see Moravec 2000). In Italy, C. hepaticum was detected in one dog from the urban area of Milan, where positive cases were also found in Rattus norvegicus Berkenhout (Ceruti et al. 2001).

The aim of this work is to report what, as far as we know, is the first case of hepatic capillariosis in a red fox (Vulpes vulpes) in Italy and to describe the egg shell structure of $C$. hepaticum using scanning electron microscopy.

From February 2010 to February 2012, in the framework of a larger on-going survey on endoparasites of canids, 75 livers of red foxes from northwestern Italy (Imperia and Cuneo districts) were examined. Sex, age, weight and geographical origin of each animal were registered. The liver was first examined grossly to detect lesions. Gall bladders and bile ducts were examined separately. The gall bladders were then transferred into a Petri plate, opened and observed under a stereomicroscope for the detection of adult parasites. The mucosa was washed in $50 \mathrm{ml}$ of normal saline solution; the sediment obtained after 30 minutes in a conical beaker was centrifuged $(2500 \mathrm{rpm} \times 10 \mathrm{~min})$ and observed under a dissecting microscope (magnification $40 \times$ ). Liver lobules were sliced and smears were prepared. Thereafter, the entire liver was dissected along the bile ducts under a stereomicroscope, the liver was washed in a conical beaker and the washing liquid was submitted to the same sedimentation procedure as described above. Morphological and morphometric analyses of eggs were performed with light and scanning electron microscopy (SEM). For SEM, eggs were isolated by flotation in a zinc sulphate solution (S.G. 1.350) and sieved, following the technique described in Al-Sabi et al. (2010), then mounted on aluminium stubs, air dried, gold coated with the sputtering technique, observed and photographed.

Among the examined 75 fox livers, one was infected with C. hepaticum. The positive fox was found in Borgo San Dalmazzo, Cuneo district. A morphological and morphometric analysis was carried out using light microscopy to identify eggs.

Address for correspondence: F. Macchioni, Department of Veterinary Science, University of Pisa, Viale delle Piagge 2, 56124 Pisa, Italy. Phone: +39 50 2216951; Fax: +39 50 2216941; E-mail: fmacchion@vet.unipi.it 

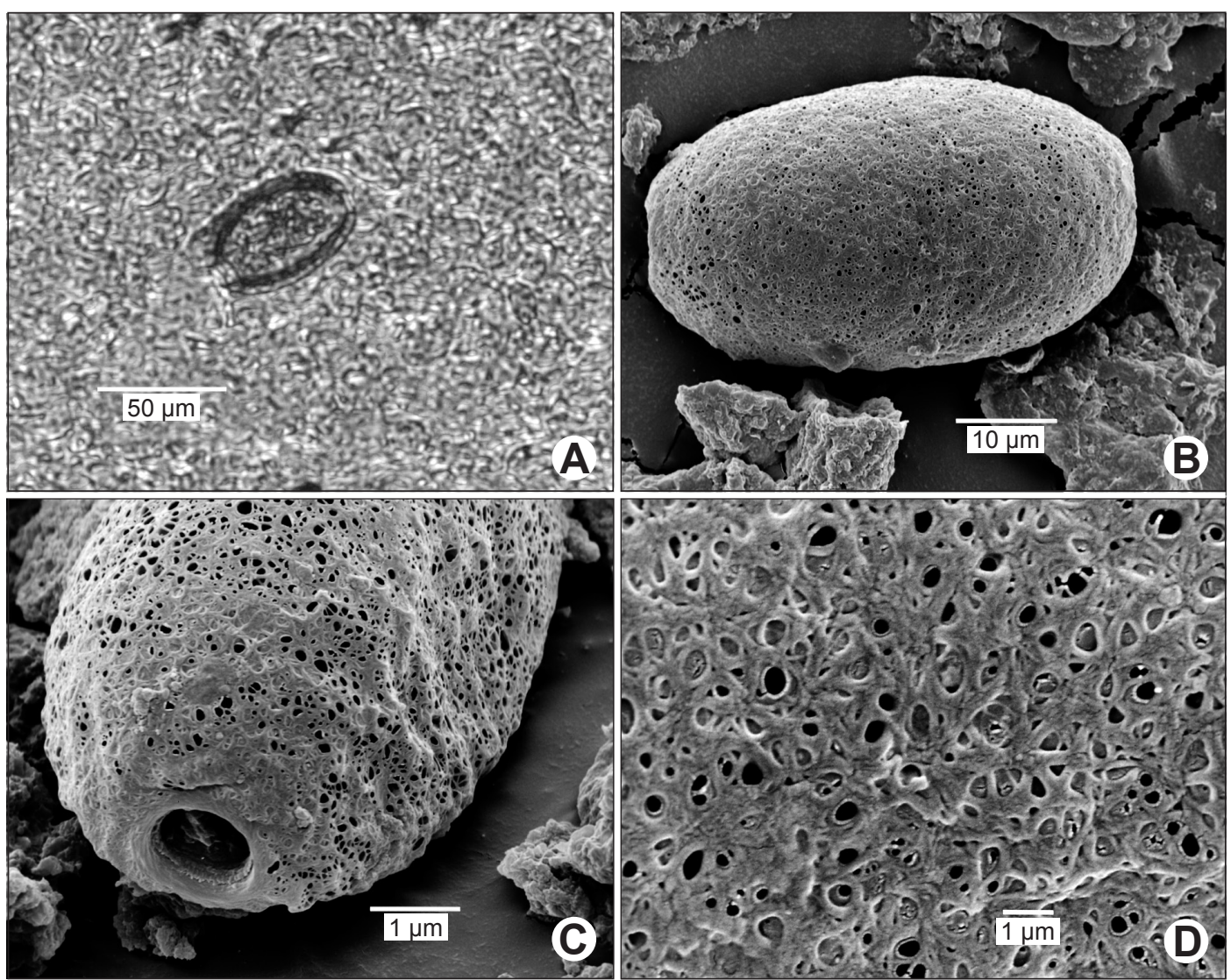

Fig. 1. Light and scanning electron microscopy of eggs of Calodium hepaticum from a red fox (Vulpes vulpes). A-egg of C. hepaticum detected using light microscopy of the liver; B - egg of C. hepaticum observed with scanning electron microscopy (SEM); C - detail of the polar plug with SEM; D - detail of the egg surface observed using SEM.

The eggs measured $54-65 \times 22-33 \mu \mathrm{m}$ and showed the typical barrel-shaped morphology with a double shell (outer and inner) and polar plugs, which did not protrude beyond the outer shell (Fig. 1A). SEM observation has revealed irregularly distributed small pits on the egg shell surface, which give the eggs a porous appearance (Fig. 1 B-D).

SEM also allowed a better observation of the external structure of the shell, which is the most relevant specific characteristic of eggs of capillariid nematodes (Zarnowsky and Patyk 1960, Conboy 2009). The appearance of the egg shell observed in the present study corresponds to the one described by Grigonis and Solomon (1976), who studied the eggs of C. hepaticum, and also observed the beam-like network of the outer region of the fibrous component. The egg shell of C. hepaticum differs from the egg shell of closely related trichinelloid species that have been studied, such as Eucoleus aerophilus (Creplin, 1839) (syn. Capillaria aerophila), Eucoleus boehmi (Supperer, 1953) (syn. Capillaria boehmi), Paracapillaria philippinensis (Chitwood, Velasquez et Salazar, 1968) and Trichuris vulpis (Froehlich, 1789) - Sukontason et al. (2006), Traversa et al. (2011), Magi et al. (2012). The eggs of E. aerophilus, E. boehmi and P. philippinensis show a net-like surface like $C$. hepaticum, but net patterns are markedly different and the surface of the egg shell of $T$. vulpis is completely smooth. Additional differences can be seen in the size and morphology of the plugs.
Another related group of nematodes, the species of which possess similar barrel-shaped eggs, is Trichosomoididae. The egg surface of Huffmanela huffmani Moravec, 1987 of this family has been examined using SEM and the shell was shown to bear characteristic spikes, which are not present in capillariids (Žd'árská et al. 2001). In addition, the eggs of a newly described species of Huffmanella, H. oleumimica Ruiz, Ray, Cook, Grace et Bullard, 2013, are covered with unevenly dispersed, minute, stub-like spines on the egg shell (Ruiz et al. 2013).

All capillariid eggs are characterized by a similar barrel shape with polar plugs and thus eggs of different capillariid species and T. vulpis can be misdiagnosed. Since specific diagnostics of all capilariid species using molecular markers is yet to be developed (Di Cesare et al. 2012, Guardone et al. 2012), SEM can help in species identification.

This study extends the host range of $C$. hepaticum because the red fox is reported as a new potential host of the parasite. In Italy, this nematode was found in rodents in Sicily (Milazzo et al. 2010) and in Lombardy (Ceruti et al. 2001); its presence in other wild and domestic animals cannot be excluded. The carcass of an infected fox may be a source of infection for animals with scavenging behaviour and may thus contribute to environmental contamination with $C$. hepaticum eggs. The population increase of foxes in urban and suburban areas may represent, through carcasses decomposition or spurious infections, 
a ource of infection for urban rodents and other animals, and occasionally for man.

More than 160 human infections caused by C. hepaticum have been reported worldwide, the majority of which in children under 5 years of age (Fuehrer et al. 2011); human cases have also been reported in Italy (Cislaghi and Radice 1970, Pampiglione and Conconi 1970). The present finding of C. hepaticum in a fox in northwestern Italy suggests the need for studies on rodent populations in this area, which are presently lacking, to assess the real risk of human infection with C. hepaticum.

\section{References}

Al-Sabi M.N.S., Deplazes P., Webster P., Willesen J.L., DavIDson R.K., Kapel C.M.O. 2010: PCR detection of Angiostrongylus vasorum in faecal samples of dogs and foxes. Parasitol. Res. 107: 135-140.

Brander P., Denzler T., Henzi M. 1990: Capillaria hepatica bei einem Hund und einem Igel. Schweiz. Arch. Tierheilkd. 132: 365-370.

Ceruti R., Sonzogni O., Origgi F., Vezzoli F., Cammarata S., Giusti A.M., Scanziani E. 2001: Capillaria hepatica infection in wild brown rats (Rattus norvegicus) from the urban area of Milan, Italy. J. Vet. Med. B. 48: 235-240.

Cislaghi F., Radice C. 1970: Infection by Capillaria hepatica. First case report in Italy. Helv. Paediatr. Acta 25: 647-654.

Conboy G.A. 2009: Helminth parasites of the canine and feline respiratory tract. Vet. Clin. N. Am. Small Anim. Pract. 39: 1109-1126.

Di Cesare A., Castagna G., Otranto D., Meloni S., Milillo P., Latrofa M.S., Paoletti B., Bartolini R., Traversa D. 2012: Molecular detection of Capillaria aerophila, an agent of canine and feline pulmonary capillariosis. J. Clin. Microbiol. 50: 1958-1963.

FARHANG-AzAD A. 1977: Ecology of Capillaria hepatica (Bancroft, 1893) (Nematoda). II. Egg-releasing mechanism and transmission. J. Parasitol. 63: 701-706.

Fuehrer H.P., Igel P., Auer H. 2011: Capillaria hepatica in man - an overview of hepatic capillariosis and spurious infections. Parasitol. Res. 109: 969-979.

Grigonis G.J., Solomon G.B. 1976: Capillaria hepatica: fine structure of egg shell. Exp. Parasitol. 40: 286-297.

Guardone L., Magi M., Macchioni F., Deplazes P., Mathis A. 2012: Genetic characterization of carnivore capillariids. XXVII SOIPA (Società Italiana di Parassitologia) National Congress, Alghero (SS), 26-29 June 2012, Mappe Parassitologiche 18: 219.

Lloyd S., Elwood C.M., Sмiтн K.C. 2002: Capillaria hepatica (Calodium hepaticum) infection in a British dog. Vet. Rec. 151: 419-420.

López-Neyra C.R. 1947: Los Capillariinae. Mem. Real Acad. Sci. Exact. Fís. Nat., Madrid, 248 pp.

Magi M., Guardone L., Prati M.C., Torracca B., Gabrielli S., Macchioni F. 2012: First report of Eucoleus boehmi (syn. Capillaria boehmi) in dogs in north western Italy, with light and scanning electron microscopy description of the eggs. Parasite 19: 433-435.
Milazzo C., Ribas A., Casanova J.C., Cagnin M., Geraci F., Di Bella C. 2010: Helminths of the brown rat (Rattus norvegicus) (Berkenhout, 1769) in the city of Palermo, Italy. Helminthologia 47: 238-240.

Moravec F. 2000: Review of capillariid and trichosomoidid nematodes from mammals in the Czech Republic and the Slovak Republic. Acta Soc. Zool. Bohem. 64: 271-304.

Moravec F. 2001: Trichinelloid Nematodes Parasitic in ColdBlooded Vertebrates. Academia, Prague, 429 pp.

Pampiglione S., Conconi G. 1970: Primo caso di capillariosi epatica osservata nell'uomo in Italia. Parassitologia 112: 125-134.

Ruas J.L., Soares M.P., Farias N.A.R., Brum J.G.W. 2003: Infecção por Capillaria hepatica em carnívoros silvestres (Lycalopex gymnocercus e Cerdocyon thous) na região sul do Rio Grande do Sul. Arq. Inst. Biol. 70: 127-130.

Ruiz C.F., Ray C.L., Cook M., Grace M.A., Bullard S.A. 2013: A new species of Trichosomoididae (Nematoda) from skin of red snapper, Lutjanus campechanus (Perciformes: Lutjanidae), on the Texas-Louisiana shelf, northern Gulf of Mexico. J. Parasitol.: in press.

Skryabin K.I., Shikhobalova N.P., Orlov I.V. 1957: [Trichocephalids and Capillariids of Animals and Man and the Diseases Caused by Them.] Essentials of Nematodology 6. Publ. House of the USSR Acad. Sci., Moscow, 587 pp. (In Russian.)

Stokes R. 1973: Capillaria hepatica in a dog. Aust. Vet. J. 49: 109. Sukontason K.L., Sukontason K., Piangjai S., Vogtsberger R.C. 2006: Ultrastructure of eggs of Paracapillaria (Crossicapillaria) philippinensis and evidence related to its life cycle. Micron 37: 87-90.

Traversa D., Di Cesare A., Lia R.P., Castagna G., Meloni S., Heine J., Strube K., Milillo P., Otranto D., Meckes O., SCHAPER R. 2011: New insights into morphological and biological features of Capillaria aerophila (Trichocephalida, Trichuridae). Parasitol. Res. 109: 97-104.

Wobeser G., Rock T.W. 1973: Capillaria hepatica (Nematoda: Trichuridae) in a coyote (Canis latrans). J. Wild. Dis. 9: 225226.

Zarnowsky E., Patyk W. 1960: On the independence of the species Thominx böhmi (Supperer, 1953) and its occurrence. Acta Parasitol. Pol. 8: 205-213.

Žďárská Z., Huffman D.G., Moravec F., NebesáŘová J. 2001: Egg shell ultrastructure of the fish nematode Huffmanela huffmani (Trichosomoididae). Folia Parasitol. 48: 231-234.

Received 25 September 2012

Accepted 22 October 2012 